\title{
The Impact of Asset Management on Company's Operational Performance A Case of Horizon Construction Ltd
}

\author{
Gikongo Kayitare Sam
}

Master of Business Administration (Accounting and Finance Option) of the University of Kigali

\begin{abstract}
The efficiency of asset management for various reasons has been the focus for companies, Managers and investors doing construction businesses. The main objective of this research is to ascertain the effect of asset management practices on operational performance within Horizon Construction Ltd. To accomplish the main objective, three specific objectives were formulated. These include; to analyze the effect of standards compliance operational performance within Horizon Construction Ltd; to examine the effect of assets maintenance on operational performance within Horizon Construction Ltd and to assess the effect of budget allocation of funds on operational performance within Horizon Construction Ltd. The related theories including the resource based theory and the contingency theory, were used and analyzed. The population of the research are 200 participants and sample size is 66 respondents. The research tools for data collection are questionnaire, interview and documentation. The findings indicated that each unit of compliance with standards do not significantly influence each unit of operational performance in Horizon Construction Ltd. There is increase in each unit of operational performance when the unit of budget allocation of funds increases at 55.7\% in Horizon Construction Ltd. There is an increase in each unit of operation performance when the unit of assets maintenance increases at $30.7 \%$ in Horizon Construction Ltd. Budget allocation of funds affects operational performance more than assets maintenance in the same perspective compliance with standards in asset management is on the third priority to affect operational performance in Horizon Construction Ltd. The results indicated that there is a positive auto-correlation between asset management (assets maintenance, compliance with standards, budget allocation of funds) and operational performance in Horizon Construction Ltd. This means that asset management can be associated with operational performance in Horizon Construction Ltd. There is a positive strong correlation between asset management and operational performance $(\mathrm{R}=0.993)$. The study concludes also that asset management (compliance with standards; assets maintenance and budget allocation of funds) had positive and significant effect cost efficiency in Horizon Construction Ltd. This means that as much as asset management is taught to the employees, there was an improvement on operational performance that will results in cost effective use of resources in Horizon Construction Ltd. This indicates that once employees are integrated in asset management system they will have accountability that will contribute to operational performance toward the achievement of the set goals within horizon construction Ltd.
\end{abstract}

\section{Introduction}

In modern world, the companies need to use their resources both effectively and efficiently which will lead to the companies' goals achievement. Companies with expensive equipment's such as big factories that produce products, have to pay attention to their daily operating equipment's in avoiding their misuse that can cause them to break-down or less productive that can lead to the failure of meeting both company holder's and other stakeholder's goals achievement. Therefore an effective asset management system should be kept that will lead to the good company's operational performance (Enmon, 2014).Construction industry is one of the largest sectors of the United Kingdom (UK) economy. It contributes almost $£ 90$ billion to the UK economy (or 6.7\%) in value added, comprises over 280,000 businesses covering some 2.93 million jobs, which is equivalent to about $10 \%$ of total UK employment (James \& Isabel, 2013). Over the last five years there have been some dramatic changes in the construction market. Businesses across many parts of the world were faced with unprecedented challenges arising from a number of factors. These included rising prices of raw materials, limited availability of funding, corporate failures arising from the inappropriate 
management of risks, government spending cuts and falling consumer spending coupled with new accounting standards and regulatory requirements.

According to Jonathan Hook and Michael Cracknell (2013), late payment is also a key obstacle facing construction SMEs. Contractors in the construction industry are often not paid for their work until sometime after it is done. It is not unusual for lower tier supply chain members to have to wait for up to 100 days to receive payment. This harms the company's cash flow and means they often need to rely on borrowing to pay for materials and labor. According to the Construction Trade Survey late payment is the single most important issue affecting construction businesses, with only $5 \%$ of specialist contractors being paid within 30 days. The Small Business Survey (2012) also found that, compared to other sectors, late payment is a particular issue for construction contracting SMEs. Some 33\% of construction contracting SME employers state that customers paying them later than they require them to in their normal terms of business are a big problem. This is compared to $19 \%$ of all SME employers citing late payment as a big problem.

The field of asset management in less developed countries is not well tapped in literature, yet it is a field that is constantly undergoing changes, specifically in construction companies due to various reasons (Arcadis L. , Asset Management for the Road sector, 2014). The construction industry significantly affects the economy, the environment and society as a whole. It touches the daily lives of everyone, as quality of life is heavily influenced by the built environment surrounding people. The construction industry serves almost all other industries, as all economic value creation occurs within or by means of buildings or other constructed assets. As an industry, moreover, it accounts for $6 \%$ of global GDP. It is also the largest global consumer of raw materials, and constructed objects account for $25-40 \%$ of the world's total carbon emissions (Allan W, 2016).

In Rwanda, for example, the construction industry plays a significant role in the socio-economic development of the nation. This is because it provides the physical infrastructure that is central to the country's economic development. Its activities create business for suppliers and manufacturers and it provides employment to professionals, semi-skilled and unskilled labor. It uses various assets and asset management approaches for its businesses endeavors (Fred, 2018). The construction industry contributes more than 7\% to the national GDP with Private and public works are growing at $9.4 \%$ since 2014 (Onyango, 2019).

So what is an asset? What is asset management? According to the ISO, an asset is an item, thing or entity that has potential or actual value to an organization, where the value can be tangible or intangible, financial or non-financial, and includes consideration of risks (Adalia \& Marolle, 2017). Because of this, assets are therefore very crucial for both individuals and organizations as they cannot live without them.

Asset management, Kuhn et al. (2011) define it as the broad strategic method of documenting and organizing of the assets as well as using collected information to assist the company in making cost-effective investment decisions. It is a business process as it applies a decision-making framework that covers an extended time. Its approach bases on the best practices borrowed from the areas of economics, engineering, and business.

According to Bloom and Kuhn (2011) remarked, the goal of asset management is cost-effective resource allocation and programming decisions. This is because it allows companies to focus on assets comprehensively. That is to say, it allows the company decision makers to have a wider picture so as to make decisions correctly. Therefore, a well-designed asset management system has to be a vital element of companies so as to enable the mobility of clients, planning for future improvements, as well as being accountable and responsive to the assets and investments. This is because, it provides the best strategy for future readiness so as to ensure that companies achieve their goals of enhancing safety, increasing the value of assets, as well as expanding economic opportunities.

Asset management is viewed as "a way to plan in advance by substantiating the validity of a decision with information and measurements" Mann et. al. 1988. It provides components of a rational decision as-goals (review of values and intentions), options (reflection concerning the variety of selections available), facts (the pursuit of information), effects (evaluation of the pros and cons for each decision, and finally the review 
(the implementation strategy and feedback of conclusions).A properly managed assets result in yielding long term performance as well as value and the reverse leads to under performance and loss for the company. Thus many factors are that affect the management of assets (Nel \& Jooste, 2010).

Some factors that affect the asset management are highlighted by Arcadias as:-increasing safety and regulatory requirements, extreme weather conditions due to climate changes, scarce capital reserves due to high operating capital costs, high customer expectations, rapid urbanization, as well as aging infrastructure and new infrastructure development (Arcadis L., 2016).

Surprisingly, some organizations are not aware of the assets they possess and the condition they are in for example, $80 \%$ of asset owners have been found by a survey to lack awareness of the assets they own, the nature of conditions the assets are in, the assets that need maintenance as well as the required budget for their maintenance or purchase (Arcadis.K, 2015). In Vietnam, literature indicates that many large contractors in Vietnam are lacking an effective method to measure their performance and identify weaknesses and threats. These authors provide solutions that can help construction companies to have effective performance.

Operational performance on the other hand, is defined in the literature as the measurable aspects of the outcomes of an organization's processes, such as reliability, production cycle time, customer satisfaction and inventory turns. It affects business performance measures such as market share and customer satisfaction (Khan \& James, 2014).

Kaplan and Norton (1992) posit that operational measurements of management are needed when dealing with internal processes, customer satisfaction, as well as activities directed at improvement and innovation in the company, which lead to future financial revenues. According to Tsikriktsis (2007). The overall impact of operational performance on profitability has been largely neglected. Schefczyk (1993) studied the impact of productivity on financial performance in the airline industry. Using data envelopment analysis (DEA), he combined multiple outputs and inputs to develop a measure of total factor productivity for a cross section of 15 international air carriers, and he found that productivity was linked to return on equity. Furthermore, Smith and Reece (1999) examined the relationship between strategy, productivity, and business performance through field-based research in a wholesale distribution service setting. They found that productivity (measured by average monthly sales documents over number of employees, average monthly sale line items over number of employees, and yearly dollar sales per warehouse square footage) was linked to financial performance.

Azim, Ahmed \& Khan, (2015) stress that upgrading or replacing outdated equipment and property may be the way to increase the fixed-asset turnover ratio. The company also may be able to refinance any loan on the assets to liquidate the capital. Reducing expenses will cause a low fixed-asset turnover ratio, such as costly repairs, by providing regular maintenance to property. According to the Ministry of infrastructure (2009), Rwanda's construction industry is underdeveloped and plagued with a host of problems, which includes a lack of management, technical capacity, access to credit facilities and work opportunities.

The majority of the construction companies face many challenges and problems, such as workmanship defects, delay, and cost overrun in implementing their projects in all over the world. Since over the past three decades, the globalization and competition have been increasing (Neyestani \& Uanzon, 2016). Thus, the globalization and competition are the most important reasons that each construction company needs to improve and correct its system for achieving its objectives by management tools.

The construction industry everywhere faces problems and challenges. However, in the developing countries, these difficulties and challenges are present alongside a general situation of socio-economic stress, chronic resource shortages, institutional weaknesses and a general inability to deal with the key issues.

Ofori and Toor (2012) considered leadership to be the missing ingredient in the recipe for construction industry development, owing to the nature of these countries, construction industries and their operating environments. The features of the construction industry, process and project make leadership even more essential. The industry includes many stakeholders with often conflicting objectives. The projects are 
expensive, technically demanding and take a long time to complete: the project teams are large and diverse. The process is long and involves many discrete and interrelated tasks. In developing countries, given the influence of construction products on long-term socio-economic development, poor Nature of the Construction Industry. Thus, effective leadership is critical in construction.

The construction companies face problems related to poor quality of construction and infrastructure development. Thus, the observation is that government projects have been left without being completed.

\section{Literature}

This theory was propounded by Ainuddin (2011). Stems from the principle that the source of firms' competitive advantage lies in their internal resources, as opposed to their positioning in the external environment. That is, rather than simply evaluating environmental opportunities and threats in conducting business, competitive advantage depends on the unique resources and capabilities that a firm possesses (Barney, 1995). The resource-based view of the firm predicts that certain types of resources owned and controlled by firms have the potential and promise to generate competitive advantage and eventually superior firm performance

Thus, according to the resource-based theory, managing strategically involves developing and exploiting a firm's unique resources and capabilities and continually maintaining and strengthening those resources. The theory asserts that it is advantageous for a firm to pursue a strategy that is not currently being implemented by any other competing firm. Such strategic resources must either be rare, hard to imitate or not easily substitutable. The theory predicts that possession of strategic resources provides an organization with an opportunity to develop competencies over its rivals hence resulting in good performance. It further predicts that strategic resources and capabilities enable organizations to enjoy excellent performance.

Khalid and Gardiner (2014) supported the Resource-based View (RBV) of the firm is a strategic management theory that is widely used by managers in project management. The RBV has to date been a promising theory that examines how resources can drive competitive advantage, especially project management (PM) capabilities that have been customized to a specific organizational environment and developed over time. However, despite the advantages offered by the RBV to practitioners and scholars alike, the theory has been under attack by opponents claiming that there is an over enthusiasm for what the theory can deliver, especially concerning lack of criteria for generalizability and definitional ailments. Therefore, it gives an overview of the supporters and opponents of the application of the RBV in PM practice and research.

Borrero (2010) criticized the Resource-Based View (RBV) literature seems to raise more questions than it provides answers about strategic choices that enable a firm to generate a competitive advantage (Connor, 2002). Appealing indeed-especially in a theoretical fashion-but often ineffective as a management tool for practitioners, the RBV has provoked ardent debates amongst strategy researchers that are still far from being settled. And yet, despite having been the target of some harsh questioning, this perspective has also influenced much of the last decade's studies on strategy. Areas of great relevance and actuality for the organizational sciences, such as the Knowledge-Based View of the firm Grant (1996) or the Dynamic Capabilities Theory (Eisenhard \& Martin, 2000), strongly rely on resource-based strategies, highlighting the main role played by the RBV in the construction of strategic theory. A critical analysis of the RBV that assesses its possible limitations and virtues in the context of current academic and management trends can shed some light not only on the state of the art in RBV-related studies but also on the bearing that this research might follow in years to come.

Thompson (2010), in his classic organization action model portrayed the basic problem of an organization as achieving originality in an uncertain world. Organizations are created to pursue some desired outcomes, yet they are faced with technologies and environment of varying levels of uncertainty which limits their ability to plan and execute actions to achieve the desired ends. Thompson viewed organizations as open systems fundamentally dependent on an environment over which they have only limited control.

Narbandian (2016) supported the contingency theory that in the lineage of organization theory, contingency approaches have incorporated open systems models (Katz \& Kahn, 1966). and succeeded the human 
relations orientation (Roethlisberger \& Dickson, 1997) and principles of management (Gulick \& Uruick, 2001). While the thrust of professed practice and theory in personnel administration remains at the principles level, some academicians paralleling theoretical trends in organization theory have adopted open systems theory for a better understanding of public personnel management (Leving \& Nigro, 1995). Since the notion of merit principles in personnel management represents much more of a normative and institutionalized movement than was embodies in the principles of management one might hesitate to fully endorse the parallel progression between organization theory and theories of personnel management. Nevertheless, if there is some value in the analogy a contingency model of public personnel management seen worth pursuing.

The contingency theory was criticized by Duill (2010) because it revolves around the concept that a single best way of structuring an organization does not exist. The suitable form is defendant on the type of environment within which an organization exists. Therefore, management may correctly utilize a variety of approaches in order to perform assorted tasks, because different types of organization are required in different types of environments. The management staff in an organization must keep one critical factor in mind. They must make the process of adapting their organization to its environment the underlying principle of all their work.

\section{Empirical Review}

The asset management highlights that to have an efficient and effective asset management, the organization has to understand and communicate the goals of the asset management program and ensure strong leadership and stakeholder support; recognize the organizational implications of an asset management program to ensure long- term success; implement a framework that integrates all asset related functions, activities, and financials to achieve true ownership across all levels of the organization; strike the right balance between financial performance, risk management, and operational performance; leverage information technology to enable organizational change, optimize business processes, and support informed decision making; as well as rely on best practices risk- based prioritization, performance-driven asset management, and standards (Arcadis, 2015) .

The theory emphasized by (Nel.T, 2016) Asset management theoretical framework is that of the asset management value theory. The processes of management if well executed can add value to an organization. The value adding potential of strategic asset management is stressed as: Asset management is being a valueadding pursuit when carried out in a strategic approach. The value is enhanced by productivity strategy processes and through effective and efficient use of an organization's assets. Asset management is the process of organizing, planning, designing and controlling the acquisition, care, maintenance, refurbishment, and disposal of infrastructure and engineering assets to support the delivery of services. It is a systematic, structured process covering the whole life of physical assets. Systematic integration of advanced and sustainable management techniques into a management paradigm or way of thinking, with Primary focus on the long-term life cycle of the asset and its sustained performance, rather than on short- term, day-to-day aspects of the asset. Is a mind-set which sees physical assets as objects and systems which respond to their environment, change and normally deteriorate with use, and progressively grow old then fail / stop working. It is recognition that assets have a life cycle. It is an approach that looks to get the best out of the assets for the benefit of the organization and/or its stakeholders (Kuhn, 2011).

Asset management refers to applying performance management principles to the management of the construction physical assets and provides a strategic approach for the preservation, rehabilitation and maintenance of these assets. The asset management framework (2004) echoes in and defines asset management as the decision making process that determines what asset to use, where to use it and how to use it. It is the process that weighs up the advantages and disadvantages of utilizing resources in a specific way against the risk of not doing so and not achieving the set goal in the shortest period and most effective way possible. It also involves the performance management (Kumar.A, 2006).

Performance management is a strategic activity that focuses on how policies, resource allocation and other decisions affect all aspects of system performance including safety, operations, environmental stewardship 
and infrastructure condition. The basic principles of performance management can be applied to all aspects of transportation system performance and to the performance of transportation agencies as well.

Asset management is the coordinated activity of an organization to realize value from assets. It involves the balancing of costs, opportunities and risks against the desired performance of assets, to achieve the organizational objectives." Asset managers conduct research, interviews, and statistical analyses of companies, markets, and trends in order to determine what investments to make or avoid on behalf of their clients. Asset managers do not generally need "asset manager" licenses, though the firms that hire these managers often require registration with one or more exchanges and/or the National Association of Securities Dealers (Davis.R, 2003).

Regulation is the management of complex systems according to a set of rules and trends. In systems theory, these types of rules exist in various fields of technics, but the term has slightly different meanings according to context (Best.R, 2003). When you have a goal and regulation for the field of construction, it is necessary to focus on the future plan of how the things was in good conditions. For this study the regulation and goal will help researcher to analyses and to get the ways of asset management was easy and how will make the impact on a company's operational performance.

Maintenance is activities required or undertaken to conserve as nearly, and as long, as possible the original condition of an asset or resource while compensating for normal wear and tear. The process of preserving a condition or situation or the state of being preserved (Delaney, 2011). The maintenance will contribute in asset management in conservation and stabilize some materials and to analyze the situation that can influence the condition and a period of construction in horizon.

The Safeguarding contribute in asset management, where is defined as those policies and procedures that "provide reasonable assurance regarding prevention or timely detection of unauthorized acquisition, use or disposition of the company's assets that could have a material effect on the financial statements." This definition is consistent with the definition provided in the Committee of Sponsoring Organizations (COSO) of the Tread way Commission's Addendum, asset management safeguarding of assets against unauthorized acquisition, use or disposition is a process, effected by an entity's board of directors, management and other personnel, designed to provide reasonable assurance regarding prevention or timely detection of unauthorized acquisition, use, Safeguard assets can be the method of protecting and maintaining a company's daily business operations for that reason why the safeguard assets will contribute in asset management (T.W, 2000)

A budget allocation is the amount of funding designated to each expenditure line. It designates the maximum amount of funding an organization is willing to spend on a given item or program, and it is a limit that is not to be exceeded by the employee authorized to charge expenses to a particular budget line. In a domain of companies, the budget allocation is necessary for asset management where it can contribute in management like buying materials in case of immediate support (Karim, 2013).

Operational performance for firm's performance measured against standard or prescribed indicators of effectiveness, efficiency, and environmental responsibility such as, cycle time, productivity, waste reduction, and regulatory compliance. There are many ways to measure the performance of a company so as to determine if it is doing well. The most common method to look at its gross or net profit. This however, is not always a reliable way to determine the performance of a company. According to And Neely, author of the book, Business Performance Measurement. Unify Theory and Integrating Practice, There are five main operational performance objectives: speed, quality, costs, flexibility, and dependability (Truong, 2011).

The obligation of an individual or organization to account for its activities, accept responsibility for them, and to disclose the results in a transparent manner. It also includes the responsibility for money or other entrusted property for that reason why the accountability will contribute in operational performance indicators for our study (Sporta, 2018) 
Some scholars wrote on cost effectiveness uses of resources with different views but with the same related meaning .Effectiveness presents level at which the organization achieves its goals (Potocan, 2011). According to Quinn (2013), the concept of effectiveness attempts to study operations holistically (i.e. in a broader sense), namely based on the definition and understanding of organization's goals and strategies as well as adequate organization of its operations. In its broadest terms, effectiveness is seen as the level of goal achievement entirety of goals and/or partial goals) within the selected area of investigation. In this case, the investigation focuses on the operations and/or behavior of the organization as a whole and/or its parts in relation to its their environment and their goals, expectations, etc.

In the research conducted Jonathan (2013), effectiveness is defined as the achievement to which stated objectives are met, the policy achieves what it intended to achieve. The goal can be as broad or as narrow as is deemed appropriate a continuum exists, ranging from achieving very specific outputs such as increasing the number of solar heating panels installed in new houses to very general outcomes such as improving the environment or even improving community living standards or wellbeing. Effectiveness presents the level of the organization's ability to attain future goals; it thus includes efficiency and capability of adjustment to future circumstances.

According to Dhamodharan and Raman (2016), facilities layout flexibility (FLF): FLF is defined as the ability of a layout to effectively withstand various changes that arise from unceasing transformations in customers' requirements and the enterprises' internal disturbances in terms of cost and time. Facilities layout is one of the key areas, which have a significant contribution towards manufacturing productivity in terms of cost and time, in a manufacturing system.

Tompkins (2015) stated that 10-30\% of material handling cost (MHC) can be reduced by having an effective facilities layout. Benjaafar (2012) argued that a layout has a direct impact on the operational performance, as measured by manufacturing lead time, throughput rate and work-in- process. Thus it is evident that having an effective layout is critical for productivity improvement in an enterprise. Flexibility is one of the most crucial parameters for market survival in today's manufacturing environment. Flexibility can be defined as an ability of a manufacturing enterprise to respond quickly and effectively with little penalty in time, effort, cost or performance to the uncertainties and changes in customer requirements.

Productive area utilization (PAU). Designing facilities layout involves allocating the area required at appropriate location for various needed activities, which include production activities and administration activities. The production activities are related to the production at the shop floor and these are executed and supported by various elements such as machines, material storage and others in a shop floor. Hence, the area utilized for these elements is defined as the productive area (Nagalingan, 2011).

According to OECD (2011), the term cost efficiency is defined as achieving goals using the minimum less resources compared to the planned ones without decreasing the output, and without increasing any other input. Efficiency presents the level of different goals achievement within the limited available resources.

According to Yen Lee (2010), in the real world, a firm's resources are always limited. When a firm would like to provide a product or service, it must consume input resources to generate the output level. In this setting, operational efficiency is determined by the outputs produced as well as the input resources or costs consumed. Thus, we can define productivity and efficiency as:

Productivity $=$ Output/Input

Efficiency $=$ Productivity/ Productivity of best practice

In other words, productivity is the ratio of output level to the input level and efficiency is the ratio of the current productivity level to the best practice productivity level. Best practice is defined as the largest productivity achievable.

\section{Methodology}

The study employed a survey research design. This is based on the fact that the study used primary data which was collected from the respondents and this could help to get their perceptions on employees' 
perceptions of the relationship between asset management and operational performance of Horizon Construction Ltd.

The population of this study was composed the employees of the Horizon Construction Ltd. The researcher possessively considered a target population of 200 employees from this company, the selected employees are the ones that are aware of asset management from different departments of this company such as production managers, asset managers, project managers, finance managers, accountants, inventory managers, site engineers, site accountants, fleet managers and others that deal with assets of this company.

This research used stratified random sampling method in gathering information from the respondents. Under this technique the researcher ensured that the categories of all employees that are aware of asset management are included in the sample. Stratification achieved this by grouping the heterogeneous population into homogeneous subsets which ensure representative. Random sampling technique was then used to sample individual department within the stratum as it eliminates bias since each member of the target population has an equal chance or probability of being selected.

The Taro Yamane's formula was used to choose a sample size,

$$
\boldsymbol{n}=\frac{\mathbf{N}}{\mathbf{1}+\mathbf{N}(e)^{2}}
$$

Where, $\mathrm{n}=$ collected sample size, $\mathrm{N}=$ population size, and $\mathrm{e}=$ Margin of error $(\mathrm{MoE}), \mathrm{e}=0.1$ based on the research condition, the sample size was; $\boldsymbol{n}=\frac{\mathbf{2 0 0}}{\mathbf{1 + 2 0 0}(0.1)^{2}}=66$ respondents.

The sample size of 66 respondents contributed for the data collection on this study

During the data collection exercise, the researcher obtained a research permission letter from the UoK management. The sources of data of this research were the primary data and secondary data. In primary data, the questionnaire and an interview were used, where in secondary data the documentary review was used.

\section{Presentation, Analysis And Interpretation of Findings}

The first objective of this research study was to analyze the effect of standards compliance operational performance within Horizon Construction Ltd.

Findings indicate that goals and policies are set clearly in Horizon Construction Ltd (mean 4.15, SD 1.04). In perspective company's goals are well communicated and understood by all staff in Horizon Construction Ltd (mean 4.23, SD 0.67). However, staffs of Horizon Construction Ltd did not specify whether all involved or not in policies making $(3.12,1.64)$ in Horizon Construction Ltd. Company policies need a certain review based on the current situations $(3.79,1.13)$.

The above information's indicate that standards in assets management are well defined and communicated to all staffs in Horizon Construction Ltd. However, the results showed that not all staffs comply with standards.

The second objective was to examine the effect of assets maintenance on operational performance within Horizon Construction Ltd.

The findings revealed that the respondents agreed that company has a safe asset protection system (mean 4.64, SD 0.80). Company has its own skilled technicians that responsible and checking the good performance of all machines (mean 4.26, SD 1.00). The findings also showed that there is an update and checks of physical (available) company's assets and tagging (mean 4.59, SD 0.63) on one hand. Horizon Construction Ltd.'s assets are maintained regularly on the other hand (mean 3.98, SD 1.13). This indicated that employees from Horizon Construction Ltd are aware of the role of assets maintenance on operational performance field.

The third objective was to assess the effect of budget allocation of funds on operational performance within Horizon Construction Ltd. 
The findings showed that the respondents did not specify whether they agree or not that there is involvement of all staff in budget preparation (mean 3.03, SD 1.48). Horizon Construction Ltd employees have not been clear about how to make a priority of activities due to funds available (mean 3.83, SD 0.95). The findings also revealed that the employees from company did not specify that if there is flexibility or not in activities budgeting of company (mean 3.74, SD 1.52). This indicated that employees agreed that company's resources are allocated in line of policies set (mean 4.33, SD 1.01). This clearly showed that employees from Horizon Construction Ltd are aware of the role of budget allocation of funds on operational performance field.

\section{Conclusion}

The findings indicated that each unit of compliance with standards do not significantly influence each unit of operational performance in Horizon Construction Ltd. There is increase in each unit of operational performance when the unit of budget allocation of funds increases at 55.7\% in Horizon Construction Ltd. There is an increase in each unit of operation performance when the unit of assets maintenance increases at $30.7 \%$ in Horizon Construction Ltd. Budget allocation of funds affects operational performance more than assets maintenance in the same perspective compliance with standards in asset management is on the third priority to affect operational performance in Horizon Construction Ltd.

The results indicated that there is a positive auto-correlation between asset management (assets maintenance, compliance with standards, budget allocation of funds) and operational performance in Horizon Construction Ltd. This means that asset management can be associated with operational performance in Horizon Construction Ltd. There is a positive strong correlation between asset management and operational performance $(\mathrm{R}=0.993)$.

The study concludes also that asset management (compliance with standards; assets maintenance and budget allocation of funds) had positive and significant effect cost efficiency in Horizon Construction Ltd. This means that as much as asset management is taught to the employees, there was an improvement on operational performance that will results in cost effective use of resources in Horizon Construction Ltd. This indicates that once employees are integrated in asset management system they will have accountability that will contribute to operational performance toward the achievement of the set goals within horizon construction Ltd.

\section{Recommendations}

This research is aimed at improvement of operational performance in Horizon Construction Ltd as such the researcher came up with the following recommendation: Employees should emphasize the aspects of respect of budget line allocation of funds.

\section{Suggestions For The Further Studies}

This study used primary data variables of asset management and operational performance of Horizon Construction Ltd, therefore it is imperative for future researchers to conduct the same study using Horizon Construction Ltd. It can also be done by using the secondary data and quantitative variables before the inference is done.

\section{References}

1. Adalia, A., \& Marolle, D. (2017). Operational and Employees Performance of Sernian Industrial Companies with ISO 9001 Certificate. Journal of Engineering Management and Competitiveness (JEMEC), 35-43.

2. Allan W. (2016). Improvement in Construction Industry. United Kingdom: World Economic Forum.

3. Arcadis , L. (2014). Asset Management for the Road sector. Journal for management and development, 33.

4. Arcadis. (2015). The future of asset management. Washington: International journal of innovation, management and technology,.

5. Arcadis, L. (2016). Tropica City: The future of International Construction.

6. Arcadis.K. (2015). Asset management asset survey: Relative maturity asset.

7. Azzone. (2005). Enterprise risk Management and Internal audit. Portugar: Managerial Auditing Journal. 
8. Barney, F. (1995). Efficiency of Resource Managment. Washington DC.

9. Best.R, C. (2003). Workplace strategies and facilities management. London: Butterwork Heineman.

10. Connor , J. (2002). Managing Resources in Development Countries. India.

11. Davis.R. (2003). Introduction to the management of physical assets.

12. Delaney, C. (2011). Asset management to Achieve the Goals in Construction Industry. USA.

13. Eisenhard, L., \& Martin, A. (2000). Management of Resource in Bridge Building. Texas.

14. Enmon, P. (2014). Organizational performance. In Achievement of organization (p. 102). United Kingdom.

15. Fred, K. (2018). An Evaluation of Rwanda Vision 2020's Achievements. Kigali City, 55.

16. Grawtz, D. (2016). The Usefulness of Qualitative and Quantitative Approaches and Methods in Researching Problem-Solving Ability in Science Education Curriculum. Journal of Education and Practice, 10-11.

17. Gross.I. (2006). Risk Management and the Role of the audit Committee Head of Internal Audit \& Projects. England: Institute of Internal Auditors.

18. Gulick, P., \& Uruick, S. (2001). Theory of Leading an Organizations. United Kingdom.

19. James, L., \& Isabel, B. (2013). The Basic Budgeting Problem. Management, 38.

20. Kaplan. (1988). Measures that drive performance. Rio de janerio: Editora Campos.

21. Karim, A. (2013). An Evaluation of Financial Performance of Private Commercial Banks in Bangladesh. Bangladesh: Journal of business studies quarterly. .

22. Katz, L., \& Kahn, P. (1966). Achievement to Company's Organizationa. Chicago.

23. Khan, F., \& James, P. (2014). An Economic Analysis of the Sector. United Kingdom.

24. Kitaka, P. (2014). Project delays and financial implications on construction firms in rwanda a case study of construction projects for cavicon consultants based in kigali city. Kigali: Mount Kenya University Rwanda.

25. Kuhn. (2011). Research on asset management for safety and operations. Texas department of Transport.

26. Kumar.A. (2006). Strategic approach to infrastructure asset management. London: Queensland University of Technology.

27. Leving, P., \& Nigro, S. (1995). Flexibility in Business Management. Boduin.

28. M.D, A. (2015). Operational performance and profitability. Bangladesh: International journal of entrepreneurship and development studies. .

29. Mann, L. (1988). Decision making in practice. Australia: Curriculum Development Centre.

30. Mann.L. (1988). Decision making in practice. Australia: Curriculum Development Centre.

31. Mugenda. (2006). Impact of statistical analysis in companys of kenya. KENYA.

32. Nagalingan, E. (2011). Construction in Development Country. Timex.

33. Nel, F., \& Jooste, P. (2010). Effectifce of quality management System(QMS) On construction projects. International Journal of Marketing Studies, 13.

34. Nel.T. (2016). A technologically-driven asset management approach to managing physical assets. Southen Africa: South African journal of industrial engineering.

35. Neyestani, M., \& Uanzon, J. (2016). Competition in Construction Industry. United Kingdom.

36. OECD. (2010). Effective Asset Management . UK.

37. OECD. (2010). Effective of Asset Management. UK: OECD.

38. Onyango, F. (2019). Business organization between efficiency and effectiveness. International Scientific Journal, 33.

39. Potocan. (2011). Business operations between efficiency and effectiveness. Journal for management and development, $2,50-62$.

40. Roethlisberger, V., \& Dickson, K. (1997). Organisational Performance Theory. Belgrade.

41. Rosengard.F. (2011). Importance of microfinance on development of small and medium enterprises. California: Building Capacities for Change.

42. RPPA. (2014). Categorization of companies operating in the field of building and civil engineering works. Kigali: Republic of Rwanda.

43. Siborurema, J. B. (2015). The effects of projects funding on their performance in Rwanda: A case study of Bukomane-Gikoma road. International Journal of Economics, Commerce and Management, 3(8), 564-594.

44. SKORUPKA. (2008). Identification and initial risk assessment of construction projects in Poland. Poland: Journal of management in engineering.

45. Sporta. (2018). The effect of operational efficiency as a financial distress factor on Financial Performance on Commercial Banks in Kenya. Kenya: International journal of business management,.

46. Springer. (2004). International Standards for the Professional Practice of Internal Auditing. Brazile: The Institute of Internal Auditors.

47. T.W, C. (2000). Asset management in transportation research record. Washington D.C: TRB National Research Council.

48. Truong. (2011). Operational performance. Kigali: INILAK.

49. Truong, V. K. (2008). Performance measurement of construction firms in developing countries. 
50. Wasana; Rosemann. (2012). Measuring process -modelling sucess and structuring. Washington DC: Peter Bombger. 